\title{
DEVELOPMENT IN THE USE AND UNDERSTANDING OF POLITE FORMS IN CHILDREN
}

\author{
By: MARILYN A. NIPPOLD, LAURENCE B. LEONARD, and ARTHUR ANASTOPOULOS
}

Nippold, M., Leonard, L.B., \& Anastopoulos, A.D. (1982). Development in the use and understanding of polite forms in children. Journal of Speech, Language, and Hearing Research, $25,193-202$.

Made available courtesy of American Speech-Language-Hearing Association: http://jslhr.asha.org/

****Note: Figures may be missing from this format of the document

\begin{abstract}
:
In two experiments, children's use and understanding of polite forms and the relationship these abilities share with an ability to adopt the perspective of another were examined. Development in the understanding of polite forms seemed best characterized as sensitivity to the function of these forms in an increasing number of sentence types. Development in the use of polite forms could be viewed as an increasing tendency to produce more than one polite form in the same utterance and to use a wider variety of interrogative types when expressing politeness. Emergence of the use and understanding of politeness in speech at age 3 seemed related to an emerging ability to adopt the perspective of another. However, development of politeness beyond this age seemed related only to a form of perspective taking in which knowledge of social roles plays a part.

\section{Articles:}

Children's development of politeness has been the focus of some recent investigations in child language. The importance placed on the study of politeness in children can be traced to two sources. One influence has been linguistics. During the past decade, a number of linguists have focused on the nature of adult pragmatic competence. This work has led to the view that politeness is a fundamental component of one's ability to communicate with others (Lakoff, Note 1). In turn, investigators in the area of child language have attempted to determine how and when politeness is acquired by children.
\end{abstract}

The second influence has been recent research on children's ability to tailor their speech to the needs (e.g., Maratsos, 1973) or the age (e.g., Shatz \& Gelman, 1973) of the listener. This research has suggested that young children are considerably more sensitive to their listeners than previously presumed. Since polite forms seem to be used primarily for the benefit of the listener, such forms have served as a focal point in a number of subsequent studies.

Recent studies of politeness in children have contributed substantially to an understanding of how children make use of and comprehend a variety of polite forms in speech. The literature dealing with children's use of polite forms has made it clear that please appears quite early in children's speech (Read \& Cherry, 1978), that children make greater use of indirect forms of requests (e.g., interrogatives such as "Can I have some milk?") with increasing age (Bock \& Hornsby, 1977; Ervin- Tripp, 1977; Garvey, 1975), and that children use a greater variety of politeness devices (e.g., please, intonation, interrogatives) with increasing age (Bates \& Silvern, 1977). 
Children's understanding of polite forms has been studied most frequently in tasks requiring the child to judge the relative politeness or "niceness" of stimulus sentences. Children's overall ability to make judgments based on politeness has been found to increase with age (Bates \& Silvern, 1977). Specifically, it appears that please is judged as a polite form at a relatively young age (Bates, 1976; Makoid, 1977), whereas the use of formal you (a feature not operative in English) is not judged as polite until much later (Bates, 1976).

Although much has been learned about children's use and understanding of polite forms, a number of questions remain unanswered. Studies of children's developing use of polite forms have focused on rather global units of behavior, such as the presence or absence of please or the interrogative. Finer distinctions, such as that between different types of interrogatives (e.g., "Could you give me a cookie?" vs. "Can I have a cookie?") have not yet been examined. In addition, politeness devices have been studied singly, but not as they may operate in combination, as in "Can I have some milk, please?"

Another issue in need of exploration is the basis of the child's acquisition of polite forms. Politeness constitutes more than the ability to comprehend and produce particular linguistic forms. As noted by Bates (1976) and Reeder (1980), polite forms are used with the listener's potential reactions in mind, and therefore reflect the speaker's sensitivity to the perspective of another. Thus, the ability to understand and produce polite forms might be expected to relate to a more general ability to adopt the perspective of others. In fact, recent investigations of children's performance on perspective-taking tasks (e.g., Borke, 1975) suggested that the ability to adopt a different perspective may emerge at the approximate age (3 years) at which children have been found to acquire early forms of politeness (e.g., Bates, 1976). However, to our knowledge, no study examining children's politeness skills has incorporated an independent assessment of the children's perspective-taking ability.

The purpose of the first experiment reported in this paper was (a) to examine children's understanding and use of polite forms at a level of analysis capable of revealing subtle differences among age groups, including those involving the use of politeness devices in combination; and (b) to determine whether children's emerging understanding and production of polite forms relate to a more general ability to take the perspective of another. In a follow-up experiment reported in this paper, we examined the relationship between perspective-taking ability and further development in the use and understanding of polite forms.

\section{EXPERIMENT 1}

METHOD

\section{Subjects}

Sixty children served as subjects, with 20 at each of the following age levels: 3 years (mean age $=3: 7$ ); 5 years (mean age $=5: 4$ ); and 7 years (mean age $=7: 5$ ). There was an equal number of boys and girls at each age level. The 7-year-olds were attending elementary schools and the 3- and 5-year-olds were enrolled in preschools located in middle-income neighborhoods. All children were of normal intelligence as judged by their performance on the Columbia Mental Maturity Scale (Burgemeister, Blum, \& Lorge, 1954) and had no obvious sensory or learning deficits. All had passed a speech and language assessment. The Fluharty Preschool Speech and Language Screening Test (Fluharty, 1978) was administered to the 3and 5-year-olds, and the Stephens Oral Language Screening Test (Stephens, 1977) and Peabody Picture Vocabulary Test (Dunn, 1965) were administered to the 7-year-olds. In addition, the spontaneous speech of all 60 children was analyzed according to Lee's (1974) Developmental Sentence Scoring (DSS). 
An additional subject group was used, consisting of 20 college-educated adults (mean age $=25$ ), with an equal number of men and women. None had any obvious speech, language, or sensory. deficits. All subjects in this investigation spoke Standard American English and were monolingual.

\section{Procedures}

All subjects participated in a production task and a judgment task. In addition, the 3-year-olds participated in a perspective-taking task.

Production task. The production task was an adaptation of Bates's (1976, pp. 296-297) politeness task in which the child requested candy from an old lady hand- puppet. In the present investigation the examiner operated the hand puppet, "Aunt Mildred," and displayed a bowl of candy that "belonged" to the puppet. The examiner then told the child to "ask Aunt Mildred for a piece of candy." Following the child's initial request, the puppet paused and "whispered" into the examiner's ear. The examiner then told the child that "Aunt Mildred said she will give you a candy, but she likes it when children are very very nice to her. So ask her again for a candy and this time, ask her nicer." Following the child's second request, he/she was given a candy. The child was then told that "Aunt Mildred might even give you another candy if you ask even nicer. So this time, ask her as nice as you can." Following the child's third request, he/she was given another candy. Neither the administration of the candy nor the type of verbal feedback provided by the examiner was contingent upon the degree of politeness in the child's request.

A different production task was used for adults. The adult was told to imagine that he/she was in a cafeteria line and was to ask the server, "an elderly woman," for a piece of cake. The adults were also told to "ask even nicer" following their first and second requests.

The requests of both the children and adults were tape-recorded and transcribed. Each of the requests was then assigned a score based on the numerical politeness scale developed by James (1978). The scores used in the James scale were derived from the judgments of 40 adults who were asked to compare pairs of requests on the basis of relative politeness. Because this scale makes distinctions among 14 different request types (e.g., "Can you give me that car?" versus "Can I have that car?"; "Can I have that car, please?" versus "Give me that car, please."), these scores allowed for a detailed analysis of the subjects' use of requests. James found this scale to be sensitive to differences in the directives that children aged 4:6-5:2 addressed to different listeners. The James scale appears in Table 1. For each subject, the sum of the three requests was computed and used as the comparative measure.

Judgment task. The production task always preceded the judgment task to avoid biasing the subject's spontaneous requests. For the judgment task, also an adaptation of Bates's (1976, pp. 297-299) politeness task, the examiner operated two identical frog puppets, "Morton" and "Digby." The child was then told the following:

These frogs are going to ask you for food. Sometimes Morton talks nicer than Digby and sometimes Digby talks nicer than Morton. You be like Aunt Mildred and decide who talks nicer-Morton or Digby. Then you feed the frog who talks nicer.

The child was then instructed to put food into the mouth of the "nicer" frog. Two practice trials were given. During the first trial, one frog said in a harsh tone of voice, "Give me a candy!" while the other spoke the same request but in a soft tone of voice. The examiner either confirmed or corrected the child's choice, for example, "Yes, Digby said it nicer that time" or "No, that wasn't right. Listen again." The 
second practice trial was identical to the first except that the previously "polite" and "rude" frogs simply reversed roles.

Six experimental request pairs were then presented in the order shown in Table 2. These pairs were ordered on the basis of relative politeness from least to most subtle using the James (1978) scoring system. This ordering procedure was used to ensure that a child would not be discouraged by a more difficult judgment coming early in the task. The correct responses were randomized so that the child could not predict which frog would speak

TABLE 1. The James (1978) politeness scale used in scoring the subjects' requests during the production task.

\begin{tabular}{|c|c|c|}
\hline Polite form & Example & Politeness value \\
\hline "May I" + "please" & "May I please have some candy?" & 4.070 \\
\hline "May I" & "May I have some candy?" & 3.134 \\
\hline "Would/Could/Will you" + "please" & "Could you please give me some candy?" & 3.113 \\
\hline "Can you" + "please" & "Can you give me some candy, please?" & 2.742 \\
\hline "Can/Could I" + "please" & "Could I please have some candy?" & 2.728 \\
\hline "Would/Could/Will you" & "Would you give me some candy?" & 2.459 \\
\hline "Can you" & "Can you give me some candy?" & 1.886 \\
\hline "Can/Could I" & "Can I have some candy?" & 1.755 \\
\hline Imperative + "please" & "Give me some candy, please." & 1.688 \\
\hline "Don't" + imperative + "please" & (Not applicable in task) & 1.562 \\
\hline Imperative + explanation & "Give me some candy because I'm hungry." & 1.206 \\
\hline "Don't" + imperative + explanation & (Not applicable in task) & 1.081 \\
\hline "Don't" + imperative & (Not applicable in task) & .161 \\
\hline Imperative & "Give me some candy." & .000 \\
\hline
\end{tabular}

TABLE 2. Examples of request pairs used in judgment task with corresponding politeness values, based on James's (1978) numerical politeness scale.

\begin{tabular}{|c|c|c|}
\hline Request pair & Example & Politeness value \\
\hline $\begin{array}{l}\text { 1. Imperative } \\
\text { versus }\end{array}$ & $\begin{array}{l}\text { "Give me a nut." } \\
\text { versus }\end{array}$ & .000 \\
\hline Interrogative + "please" & "Could you give me a nut, please?" & 3.113 \\
\hline $\begin{array}{l}\text { 2. Interrogative } \\
\text { versus }\end{array}$ & $\begin{array}{l}\text { "Could you give me a nut?" } \\
\text { versus }\end{array}$ & 2.459 \\
\hline Imperative & "Give me a nut." & .000 \\
\hline $\begin{array}{l}\text { 3. Imperative }+ \text { "please" } \\
\text { versus }\end{array}$ & $\begin{array}{l}\text { "Give me a nut, please." } \\
\text { versus }\end{array}$ & 1.688 \\
\hline Imperative & "Give me a nut." & .000 \\
\hline $\begin{array}{l}\text { 4. Imperative + "please" } \\
\text { versus }\end{array}$ & $\begin{array}{l}\text { "Give me a nut, please." } \\
\text { versus }\end{array}$ & 1.688 \\
\hline Interrogative + "please" & "Could you give me a nut, please?" & 3.113 \\
\hline $\begin{array}{l}\text { 5. Imperative + "please" } \\
\text { versus }\end{array}$ & $\begin{array}{l}\text { "Give me a nut, please." } \\
\text { versus }\end{array}$ & 1.688 \\
\hline Interrogative & "Could you give me a nut?" & 2.459 \\
\hline $\begin{array}{l}\text { 6. Interrogative }+ \text { "please" } \\
\text { versus }\end{array}$ & $\begin{array}{l}\text { "Could you give me a nut, please?". } \\
\text { versus }\end{array}$ & 3.113 \\
\hline Interrogative & "Could you give me a nut?" & 2.459 \\
\hline
\end{tabular}

more politely. For half of the subjects the frog on the examiner's right hand always spoke first, whereas for the other half the frog on the examiner's left hand always spoke first. For each request pair, requests for 
four different food items (nuts, cherries, suckers, gumballs) were used. Thus; each subject made a total of 24 separate judgments.

The judgment pairs for the adults were presented without the use of the puppets and actual food items. The adults merely listened while the examiner read each of the 24 pairs of requests. The adults indicated their preference after hearing a pair by saying "first" or -second."1

A subject's preferences on the request pairs were scored according to the James (1978) system. For example, in the first pair in Table 2 , the request containing the interrogative + please was the correct choice. ${ }^{2}$

Perspective-taking task. The perspective-taking task, used with the 3-year-olds, was virtually identical to the task developed by Borke (1975). In this task, the child sat facing a table upon which a stationary display of familiar toys and objects was placed. On another table to the child's left was an identical display placed upon a revolving tray. The child was shown a small doll in a car and was told that the doll would drive around the table in front of the child and would sometimes stop and look out at the display. The child was told that each time the doll stopped, he/she was to turn the movable display so that his/her view matched the doll's view.

One practice display and two experimental displays were used. The practice display was of a large fire engine. The first experimental display consisted of three sets of objects: a house, a lake and sailboat, and a cow and horse. The second experimental display consisted of eight sets of objects: a barn, silo, farmer, and farm animals; a girl feeding chickens; pigs in a pigpen, and rabbits; trees, bushes, Indians, and cowboys; ducks in a lake; a windmill; horses pulling a wagon; and a dog in front of a dog house.

During the practice trial, the doll stopped at three positions that differed from the child's own view. After the child rotated the movable display, the examiner either confirmed or corrected the child's response. If the child's initial response was incorrect, he/she was allowed to look directly at the display from the doll's position. For those children requiring correction, each performed correctly on three consecutive practice trials following the trial on which he/she was corrected. During the experimental trials, the child was not allowed to view the display from the doll's position, and the child was given no feedback regarding the correctness of his/ her responses. Six responses were elicited from the child, three for each of the two experimental displays. The order in which the doll stopped at the various positions was randomized for each display. A response was considered correct only if the child rotated the display to clearly match the doll's view; if the display matched the child's own view or appeared random, it was considered incorrect.

\footnotetext{
${ }^{1}$ To ensure that the manner in which the requests were presented to the younger children and adults was comparable, tape recordings of requests presented to two of the 3-year-olds were randomly selected and presented-with the children's responses deleted - to 10 adults. The judgments of the adults matched those of the adult subjects reported in the Results section.

${ }^{2}$ An effort was made to guard against the possibility that additional features of politeness such as pitch or prolongation were unintentionally added to the request classified as the more polite request of the pair according to the James (1978) system. Two of the recordings of imperative + please requests and two recordings of interrogative requests that had served as the less polite requests of a pair were randomly selected and paired with recordings of requests receiving lower politeness scores on the James system. Similarly, two recordings of these same request types when serving as the more polite requests of a pair were selected and paired with recordings of requests receiving higher politeness scores. The pairs were then presented to 10 adults. The judgments of the adults were identical to those of the adult subjects reported in Results.
} 


\section{RESULTS}

\section{Judgments According to Age}

To examine the subjects' politeness judgments, correct judgments were analyzed by means of a mixed model analysis of variance with age as a between-subjects variable and request pair as a within-subjects variable. Because no differences according to sex were seen for any of the judgment comparisons at any age $(t .76, d f=18, p>.05)$, sex was not used as a separate variable.

A significant effect was seen for age $(F=40.81 ; d f=3,76 ; \mathrm{p}<.001)$. A least-significant difference test using the .05 level revealed a difference between each of the age levels except between the adults and $7-$ year-olds (mean $=20.75,19.90,15.95$, and 13.30 for the adults, 7-, 5-, and 3-year-olds, respectively). A main effect for request pair was also observed $(F=76.13 ; d f=5,380 ; \mathrm{p}<.001)$. Fewer correct judgments were made on the request pair imperative + "please" versus interrogative than on any of the other pairs. In addition, the pair imperative + "please" versus interrogative + "please" proved more difficult than any of the remaining pairs except imperative versus interrogative.

An age $\mathrm{x}$ request pair interaction also was seen $(F=9.63 ; d f=15,380 ; \mathrm{p}<.001)$. A summary of the subjects' performance on each of the request pairs appears in Table 3. For all ages except the 3-year-olds, the pair imperative + "please" versus interrogative proved more difficult than each of the other pairs. In addition, for the 5- and 7-year-olds, the pair imperative + "please" versus interrogative + "please" was more difficult than the remaining pairs.

TABLE 3. Mean number of correct judgments by subject age and request pair.

\begin{tabular}{|c|c|c|c|c|}
\hline \multirow[b]{2}{*}{ Request pair } & \multicolumn{4}{|c|}{ Age in years } \\
\hline & 3 & 5 & 7 & Adult \\
\hline \multicolumn{5}{|l|}{$\begin{array}{l}\text { 1. Imperative } \\
\text { versus }\end{array}$} \\
\hline Interrogative + "please" & 2.25 & 3.20 & 3.95 & 4.00 \\
\hline \multicolumn{5}{|l|}{$\begin{array}{l}\text { 2. Interrogative } \\
\text { versus }\end{array}$} \\
\hline Imperative & 1.95 & 3.30 & 3.90 & 3.90 \\
\hline \multicolumn{5}{|l|}{$\begin{array}{l}\text { 3. Imperative + "please" } \\
\text { versus }\end{array}$} \\
\hline Imperative & 2.15 & 3.55 & 3.90 & 4.00 \\
\hline \multicolumn{5}{|l|}{$\begin{array}{l}\text { 4. Imperative + "please" } \\
\text { versus }\end{array}$} \\
\hline Interrogative + "please" & 2.20 & 2.00 & 3.40 & 3.90 \\
\hline \multicolumn{5}{|l|}{$\begin{array}{l}\text { 5. Imperative }+ \text { "please" } \\
\text { versus }\end{array}$} \\
\hline Interrogative & 2.15 & .70 & .95 & 1.00 \\
\hline \multicolumn{5}{|l|}{$\begin{array}{l}\text { 6. In'terrogative + "please" } \\
\text { versus }\end{array}$} \\
\hline Interrogative & 2.60 & 3.20 & 3.80 & 3.95 \\
\hline
\end{tabular}

Comparisons across ages proved interesting. On four request pairs, the 3-year-olds performed below the level seen for the 5-year-olds. On the pair imperative + "please" versus interrogative + "please," the 3- and 5 -year-olds performed at the same level. This was due to the fact that the 5-year-olds, like the 3-year-olds, 
performed only at chance level on this pair $\left(x^{2}=.60, p>.05\right)$. Surprisingly, on the pair imperative + "please" versus interrogative, the 3-year-olds made a greater number of correct judgments than each of the older age groups. This finding could be attributed to the fact that the 3 -year-olds were performing at the level of chance $\left(\mathrm{x}^{2}=.45, p>.05\right)$ whereas the subjects ages 5 and older were below the chance level $\left(\mathrm{x}^{2}\right.$ $20.0, p<.05)$. The older subjects showed a clear preference for the request containing "please," contrary to what might be expected according to the James (1978) scoring system. The 5-yearolds performed at the level of the 7-year-olds and adults on the pair imperative versus imperative + "please," and they showed a similar tendency to judge imperative + "please" as more polite than interrogative. However, for the remaining request pairs, the 5-year-olds performed at a lower level than the older age groups. The 7-yearolds performed below the level of the adults only on the pair imperative + "please" versus interrogative + "please."

\section{Productions According to Age}

An analysis of the productions of requests revealed no differences according to sex for any of the request types at any age $(t 2.02, d f=18, \mathrm{p}>.05)$. Therefore, sex was not used as a separate variable. The subjects' requests, as scored according to the James scale, revealed a clear difference according to age $(F=10.53$; $d f=3,76 ; \mathrm{p}<.001)$. The requests of the 5-year-olds showed higher scores $\left({ }^{-} \mathrm{x}=7.26\right)$ than those of the 3 year-olds $\left({ }^{-} \mathrm{x}=4.90\right)$, and the request scores of the adults $\left({ }^{-} \mathrm{x}=8.92\right)$ and 7-year-olds $\left({ }^{-} \mathrm{x}=8.55\right)$ were higher than the scores of the 5-year-olds. No difference was observed between the scores of the 7-yearolds and adults. A summary of the subjects' productions appears in Table 4.

TABLE 4. Mean number of polite forms produced in each of the applicable James (1978) categories.

\begin{tabular}{lcccc}
\hline & \multicolumn{4}{c}{ Age in years } \\
Polite form & 3 & 5 & 7 & Adult \\
\hline "May I" + "please" & .35 & .60 & .90 & .40 \\
"May I" & .05 & .15 & .20 & .10 \\
"Would/Could/Will you" + & & & & \\
"please" & .00 & .15 & .00 & 1.60 \\
"Can you" + "please" & .00 & .00 & .00 & .00 \\
"Can/Could I"+ +"please" & .35 & .70 & .95 & .15 \\
"Would/Could/Will you" & .15 & .00 & .00 & .60 \\
"Can you" & .00 & .00 & .00 & .05 \\
"Can/Could I" & .75 & 1.30 & .95 & .10 \\
Imperative + "please" & .40 & .05 & .00 & .00 \\
Imperative + explanation & .00 & .00 & .00 & .00 \\
Imperative & .95 & .05 & .00 & .00 \\
\hline \hline
\end{tabular}

A close inspection of the particular requests used at the four age levels did not reveal any qualitative differences; every type of request used at the older ages was observed in the younger children as well. The differences among the age groups took the form of differences in the frequency with which requests with high politeness ratings were used. The most notable difference was the more frequent use of "please" in interrogatives by the older subjects. When such use was collapsed across interrogative types, this difference reached statistical significance $(\mathrm{F}=7.48 ; \mathrm{df}=3,76 ; \mathrm{p}<.001)$. The 3 -year-olds $\left({ }^{-} \mathrm{x}=.70\right)$ produced fewer of these requests than the 5-year-olds $\left({ }^{-} \mathrm{x}=1.45\right)$. The 5-year-olds' performance did not differ from that of the 7-year-old subjects $=1.85)$; however, the 5-year-olds were found to use fewer of these requests than the adults $(-x=2.15)$. The increase in the use of interrogative + "please" with age was accompanied by a corresponding decrease in the use of imperative + "please." 
Two other request types contributed to the age differences observed, although taken singly they did not yield significant differences. One type of request was the interrogative (with or without please) in which the grammatical subject was the listener (e.g., "Could you give me some candy, please?"). Such requests were used frequently by the adults. The second type of request, used more frequently by subjects aged 5 and older, involved the modal may (with or without please), as in "May I please have some candy?"

\section{Judgments and Productions According to Perspective-Taking Task Performance}

To examine the contribution of perspective-taking ability to children's emerging ability to understand and use polite forms, the 3-year-olds were divided into two groups according to their performance on the perspective-taking task. Ten 3-year-old subjects made no errors on this task. These subjects were considered to have passed the task. Each of the remaining 103 -year-olds made at least one error (range = 1-5 errors, median $=2.50$ errors) and was considered not to have passed the perspective-taking task. The two groups of 3-year-olds contained approximately the same number of boys and girls. The age range for the children passing the perspective-taking task was 3:2-3:10( $\left.{ }^{-} \mathrm{x}=3: 7\right)$. For the children who did not pass this task, ages ranged from 3:1 to 3:11 ( $\left.{ }^{-} \mathrm{x}=3: 7\right)$. To ensure that the two groups did not differ markedly in linguistic ability, the children's DSS were compared. Similar scores were observed for the children who passed $\left({ }^{-} \mathrm{x}=6.92\right)$ and did not pass $\left({ }^{-} \mathrm{x}=6.66\right)$ the perspective-taking task $(t=.48, d f=18, \mathrm{p}>.05)$.

An analysis of these subjects' performance on the judgment task revealed a significant difference favoring the children who passed the perspective-taking task $(F=10.00 ; d f=1,18 ; \mathrm{p}<.001)$. The mean number of correct judgments for the children who passed and did not pass the perspective-taking task was 15.90 and 10.70 , respectively. Neither a difference according to request pair nor an interaction was observed $(F=$ $1.16 ; d f=5,90 ; \mathrm{p}>.05)$.

When the children's request productions were compared in terms of their scores on the James (1978) scale, a significant difference was seen $(t=2.41, d f=18, \mathrm{p}<.05)$. The mean score for the subjects who passed the perspective-taking task was 6.75. For the subjects not passing the perspective-taking task, the mean was 3.04. A close inspection of the children's requests suggested that the observed difference may have been due to a compounding effect of forms that failed to reach statistical significance when analyzed separately. These included imperative + "please" ( $\mathrm{x}=.70$ vs. .20), interrogatives without "please" $\left({ }^{-} \mathrm{x}=\right.$ 1.10 vs. .80), and interrogatives + "please" ( ${ }^{-} \mathrm{x}=1.10 \mathrm{vs.} \mathrm{.30).} \mathrm{Other} \mathrm{request} \mathrm{types} \mathrm{that} \mathrm{seemed} \mathrm{to}$ distinguish the older children and adults from the younger children [i.e., "May I (please) ..." and "Could you (please) ..."] were not used with sufficient frequency by the children who passed the perspectivetaking task to have contributed to this difference.

Given the superior performance by the 3-year-olds who passed the perspective-taking task, it seemed useful to determine the extent to which these children's judgments and productions of polite forms resembled those of the 5-year-olds. The overall judgment scores for the two groups did not differ $(F=$ $.17 ; d f 1,28 ; \mathrm{p}>.05)$. However, a significant interaction with request pair $(F=5.11 ; d f=5,90 ; p<.001)$ suggested that the pattern of judgments was not the same in the two groups. A least- significant difference test revealed that the 5-year-olds made a greater number of correct judgments on three of the pairs. However, the 3-year-olds who passed the perspective-taking task made a greater number of correct judgments on the pair imperative + "please" versus interrogative. This difference was due to the belowchance performance of the 5-year-olds on this pair. 
The production of polite forms in the two groups proved quite similar. No differences were seen between the groups in their politeness scores according to the James scale $(t=.95, d f=28, p>.05)$.

\section{EXPERIMENT 2}

The results of Experiment 1 suggested that an emerging ability to understand and use polite forms in speech may reflect not only a linguistic skill, but a more general ability to appreciate the view of others. In the present experiment, we attempted to determine whether the development in the use and understanding of polite forms that continues beyond age 3 may relate to additional advances in children's perspectivetaking ability.

Although investigators agree that children show the first signs of an ability to adopt another's perspective by approximately 3 years, they have been in less agreement about how to characterize perspective-taking ability in somewhat older children. This has been due to different tasks yielding quite different results, owing to factors such as the verbal demands placed on the child (Gove \& Keating, 1979) and the complexity of the materials used (Fishbein, Lewis, \& Keiffer, 1972).

In light of such potential confounding factors, reliance upon a single measure of perspective-taking seemed tenuous. Therefore, two tasks of perspective-taking ability felt to be suitable for the age range of interest were selected.

For the first task, we used most of the same materials used in Experiment 1, but eliminated certain cues to increase the perspective-taking demands that would be placed on these somewhat older children. Recent research has suggested that children's performance on perspective-taking tasks improves when they are given the opportunity to view the stimulus display from other positions before they are asked to respond (Schatzow, Kahane, \& Youniss, 1980). During the practice trial of the task used in Experiment 1, the children had an opportunity to view the display from the doll's position. During the experimental trials, the children's responses took the form of rotating an identical display in either or both directions, stopping only when they felt they had located a position that matched that of the doll. This opportunity to see the display - or an identical one - from a variety of viewing positions made it possible for the children to respond by selecting positions from among a number of recalled positions. By eliminating this aspect of the original perspective-taking task, we reasoned that the children's responses would be dictated principally by their ability to predict, rather than recall, another's perceptions.

The second perspective-taking task differed considerably from the first. In this task, the child was asked to predict not the immediate perceptions, but the more enduring preferences of others.

\section{METHOD}

\section{Subjects}

Forty children, aged 4:1-6:8, served as subjects. The children were approximately equally distributed across the age range, with no more than three months separating any child from the next oldest or youngest child. The children were attending preschools or elementary schools located in middle-income neighborhoods. All children performed at age level on the Screening Test of Auditory Comprehension of Language (Carrow, 1973) and the Stephens Oral Language Screening Test (Stephens, 1977). In addition, all children were of normal intelligence according to their performance on the Columbia Mental Maturity Scale (Burgemeister, Blum, \& Lorge, 1954). No child exhibited any obvious sensory or learning deficits. 
The second perspective-taking task used in the experiment required the children to meet additional selection criteria. All children serving as subjects were living with both parents or were living with one parent and visited the second parent on a regular basis. In addition, each had a brother or sister between 2 and 10 years of age.

\section{Procedures}

All subjects participated in the production and judgment tasks used in Experiment 1. The same procedures were followed except that the presentation order of the judgment task items was randomized across children, and the pair imperative + "please" versus interrogative was not scored, given the above-noted problems associated with identifying a correct response on this pair.

Perspective-taking tasks. The first perspective-taking task made use of the first two displays used in Experiment 1. The first display was of a large fire engine. The second consisted of a house, a lake with sailboat, and a cow and horse. The child sat facing a table upon which the first display was placed. The child was then told that the examiner would sit at various points around the table and that the child was to select one of four pictures that depicted the examiner's view of the display. The four points corresponded to the child's view: $\left(0^{\circ}\right), 90^{\circ}, 180^{\circ}$, and $270^{\circ}$. The pictures were $5 \times 7$ inches $(12.5 \times 17.5 \mathrm{~cm})$ color photographs of the display, taken from each of the four positions around the table.

The first display served as a practice trial. For this display, the child's response received corrective feedback. However, the child was not given the opportunity to get up from his/her own chair to view the display from the examiner's position. After the child demonstrated an understanding of the task, the first display and the corresponding pictures were removed and the second display and corresponding pictures were placed on the table. For this display, the child received no feedback regarding the correctness of his/her responses. Twelve responses were elicited from the child, three responses to each of the four positions around the table. The order in which the examiner sat at each of these positions and the spatial order of the pictures representing these positions were randomized across children.

The second perspective-taking task was adapted from Flavell, Botkin, and Fry (1968). The child sat at a table on which the examiner placed a man's necktie, a pair of pantyhose, a paperback book written at an adult reading level and containing no pictures, a toy truck, and a doll. The child was asked to name each item. All children showed the ability to name each correctly. The child was then told, "We're going to pretend this is a little store. Let's pretend. If you could choose one of these gifts for your's birthday, which one would you choose?" This question was asked successively for the child's father, mother, teacher (a woman in each case), brother or sister, and self. The order was randomized across children. After the child responded to each question the examiner said, "Let's do that again. You can pick the same gift or a different one." The same question was then asked for each of the above persons, in a different random order.

Each of the child's selections was readily accepted by the examiner. However, after all selections had been made, the child was asked to explain those that seemed inappropriate. The reasons given by the children seldom justified the selections (e.g., "Mommy's a girl," as a reason for selecting the doll for the mother). However, the prevalence of plausible explanations for choosing the toy truck for a sister or the doll for a brother (e.g., "'cause she's always trying to play with my trucks") led to the decision to score both as appropriate. Only the responses to the second set of questions were used in the scoring to ensure that the children had had an opportunity to inspect all the objects. All the children performed as well or better on 
the second set of questions. The children's selections were scored according to the system used by Flavell et al. (1968). The children were placed into one of four levels, ranging from an absence of perspectivetaking to an adult level of performance. The levels were:

Level 1. The child selects for the mother and/or father the same object he/she selected for him/herself. If the objects

selected for the mother and father differ, they are both child toys and inappropriate for the sex of the parent (doll for father, truck for mother).

Level 2. The child selects child toys for his/her parents that are appropriate for sex (truck for father, doll for mother).

Level 3. The child selects adult materials for his/her parents, but selects a child toy for the teacher and/or selects an adult gift for his/her sibling (e.g., doll for teacher, necktie for sister).

Level 4. The child's selections for each recipient are age and sex appropriate (e.g., book for father and mother, pantyhose for teacher, doll for sister).

\section{RESULTS}

As expected, the children's performance on both the judgment and production tasks increased with age. When the children were divided into age groups, their performance was in line with that of the children in Experiment 1. For the judgment task, means of 13.65, 14.92, and 17.27 were seen for the 4-, 5-, and 6year-olds, respectively. For the production task, these means were 5.18, 5.89, and 7.54, respectively.

The first perspective-taking task proved quite difficult for the children. Although performance increased with age $\left({ }^{-} x=3.88,4.83\right.$, and 6.45 for the 4-, 5-, and 6-yearolds, respectively), only a single 6-year-old performed without error. Therefore, instead of examining judgment and production task performance in light of whether the children passed or did not pass the perspective-taking task, the relationship between judgment and production task performance and the number of correct responses on the perspective-taking task was examined.

A low relationship was observed between the children's performance on the judgment task and their perspective-taking performance $(\mathrm{r}=.28, \mathrm{p}<.05)$. However, this relationship did not hold when age was partialled out $(\mathrm{r}=.11, p>.05)$. Similar findings were seen for the relationship between production task performance and performance on the perspective-taking task. The low relationship seen before the contribution of age was considered $(\mathrm{r}=.22, \mathrm{p}<.05)$ was no longer observed when age was entered into the analysis $(\mathrm{r}=.07, \mathrm{p}>.05)$.

The children's performance on the second perspective-taking task also increased with age. Only 4-yearolds performed at Level 1, and performance at Level 2 was seen only in 4- and 5-year-olds. Level 3 and Level 4 performance was seen in each age group. However, instances of Level 3 decreased with age, whereas instances of Level 4 increased. Only two 4-year-olds demonstrated Level 4 performance, whereas only two 6-year-olds were at Level 3.

Because of the ordinal nature of the system used to score the children's performance on this perspectivetaking task, Kendall rank order correlations were used to examine the relationship between performance on this task and performance on the judgment and production tasks. A moderate relationship was observed between the children's performance on the judgment task and their performance on the second perspective-taking task $(r=.70, p<.001)$. This relationship diminished very little when age was 
partialled out (r .64). A similar, though somewhat lower, relationship was seen between perspective-taking performance and performance on the production task $(r=.52, p<.001)$. This relationship held after partialling out the contribution of age $(\mathrm{r}=.43)$.

\section{DISCUSSION}

The results of the present investigation add to previous findings concerning children's understanding and use of polite forms, and offer some insight into the relationship holding between these skills and the ability to adopt the perspective of others.

In the first experiment, the subjects' performance on the judgment task revealed some clear developmental trends. It appeared that the children's tendency to regard requests containing please as polite increased steadily with age. By 5 years, children showed a clear tendency to regard imperative + "please" requests as more polite than imperative requests without "please." By 7 years, this tendency extended to interrogative requests differing only in the presence or absence of please. This pattern of development, in which children are initially sensitive to the presence of please only in certain sentence constructions, would have been obscured by a more global level of analysis.

The tendency to regard interrogative requests as polite emerged somewhat more slowly than was seen for please. Five-year-olds showed a greater tendency than 3-year-olds to regard interrogatives without please as more polite than imperatives without please; however, this tendency was not as great as in the 7-yearolds. Further, when both the interrogative and imperative requests contained please, the 5-year-olds had great difficulty, performing only at the level of chance. Seven- year-olds were much better on this pair; however, even these children made a greater number of errors than the adults. This finding, too, suggests the importance of examining the sentence context in which politeness devices may appear.

The results for the judgment pair imperative + "please" versus interrogative proved interesting. For each age level at which above-chance performance was seen ( 5 years through adult), a preference for imperative + "please" was exhibited. This finding points out the need to consider a request's politeness relative to the alternatives that may be available. Several studies of children's requests have made use of scoring systems based on adult ratings. Typically, the score assigned any particular request is derived from adults' ratings of the politeness of the request independent of other possible requests (e.g., Bock \& Hornsby, 1977) or from paired- comparison ratings in which the request was judged against a number of other requests (e.g., James, 1978). These different methods of assessing the politeness of a request may yield somewhat different findings. As a case in point, the interrogative receives a higher score for politeness than imperative + "please" in the James scale. Yet even the adults in Experiment 1 showed a clear tendency to select the imperative + "please" as the more polite form.

Although the James scale may have certain limitations when scoring particular pairs of polite forms, the scores assigned to request types according to this scale were generally consistent with the judgments of the older children and adults. In addition, the James scale scores assigned to the subjects' requests during the production task also increased steadily with age. Considering these factors, and the detail in which polite forms could be examined with this scale, the advantages of the James scale seemed to far outweigh its limitations.

It should be noted that in the James scale suprasegmental features are not incorporated into the scoring system. Likewise, in the requests presented in the judgment task of the present study, we did not attempt 
to control for suprasegmental factors, except to ensure that such factors did not vary as a function of whether or not a request served as the more polite request of the pair according to the variables that were formally considered (see Footnote 2). Given the findings of Loveday (1981) that suprasegmental factors operate in politeness formulae of English, it must be recognized that the politeness judgments of the subjects in our study may have been influenced by suprasegmental cues.

The analysis of the subjects' requests during the production task revealed several developmental patterns. By 3 years of age the children were already showing some use of "please," as well as the interrogative. By age 5 the use of "please" was rarely seen in requests of imperative form. The use of interrogatives such as "Can I have some candy?" also decreased with age, beginning after age 5. However, the use of the interrogative and "please" in the same request served as a major focal point of development in the age span studied, The use of this form increased steadily with age, reaching the approximate level seen in adults by 7 years of age. This finding points out the importance of examining politeness devices as they operate in combination as well as singly. For example, Read and Cherry (1978) found no developmental trend for "please." However, they examined the use of "please" only when it operated as the only politeness marker in the child's utterance.

The detailed nature of the James scale permitted an inspection of still other considerations in the children's expression of politeness. With increasing age the subjects showed more frequent use of interrogatives with the listener as grammatical subject. In addition, the use of requests such as "May I please have some candy?" increased with age. These changes with age are particularly interesting given that these requests seem to involve no greater structural complexity than the requests which predominated at the earlier ages. For example, according to the Developmental Sentence Scoring system of Lee (1974), "Can I please have some candy?" and "May I please have some candy?" receive the same score for the main verb and interrogative reversal. The same is true for "Could I please have some candy?" and "Could you please give me some candy?" Thus, it appears that the observed differences in the children's requests were not due to linguistic factors alone.

To examine the possible role of perspective-taking in children's emerging politeness ability, the 3-yearolds' judgments and productions were examined as a function of their performance on the perspectivetaking task. For both judgments and productions, higher performance levels were seen for the children who passed this task. This finding suggests that an emerging ability to understand and use polite forms in speech may reflect not only a linguistic skill, but a more general ability to appreciate the view of others.

Experiment 2 was designed to explore the possibility that continued development in the use and understanding of polite forms beyond age three was related to further development in perspective-taking ability. Two rather distinct tasks were used: a task in which the child had to predict another person's immediate perceptions of a physically present array, and a task in which the child's prediction had to be based on more permanent preferences of other persons.

The first of these tasks was a more difficult version of the task used in Experiment 1. In this task, cues in the form of recalled viewing positions were eliminated, and the child had to rely solely on imagining the examiner's viewing position. The children's performance on this task proved to be unrelated to their performance on both the judgment and production politeness tasks. 
It seems possible that another aspect of this perspective-taking task influenced the children's performance. The children's responses took the form of selecting a photograph that best matched the view of the examiner. As such, the children's performance may have depended upon their ability to relate twodimensional representations to actual viewing positions. According to Fishbein et al. (1972), this ability is spatial in nature and may be independent of the child's recognition that another person may have a perspective that is different from his/her own. Thus, our failure to find a relationship between children's use and understanding of polite forms and their performance on this task may not be surprising. On the other hand, the finding that the superficially similar perspective-taking task in the first experiment was related to politeness ability seems due to the fact that it (a) provided an opportunity to observe a variety of viewing positions, (b) demanded little spatial skill, and hence (c) may have required little more than the child's knowledge that his/her perspective may not be shared by others.

The second perspective-taking task in Experiment 2 placed fewer perceptual demands on the children. The children were required to predict more enduring perspectives of other persons, specifically, preferences for particular objects. A relationship was seen between the children's performance on this task and their performance on both the judgment and production tasks. Although this finding suggests that development of the use and understanding of polite forms beyond age 3 may relate to continued development in perspective-taking ability, the nature of this relationship is not entirely clear. One possibility is that the two abilities are related because both require the child to consider perspectives based on more stable characteristics of other persons, such as age and sex for the perspective-taking task, and age and authority for the production task. Such an explanation could account for the lack of a relationship between politeness ability and performance on the first perspective taking task used in Experiment 2 because this task required children to consider perspectives based on immediate temporary perceptions, rather than more enduring characteristics of others. However, one problem with this explanation is that it seems unable to account for the relationship between the children's perspective-taking performance and their performance on the judgment task. In the judgment task, the children were asked to judge which of two frogs made the more polite request. The frog producing the more polite request varied from item to item. Thus, for a child to perform well on this task, he/she must have understood that a speaker's status was not a stable attribute, at least relative to another speaker.

A more likely possibility is that performance on the two politeness tasks was related to performance on the second perspective-taking task because each required the child to consider perspectives within a social domain. Selecting a gift for another, judging the niceness of a speaker's manner of requesting, and requesting objects nicely from another all involve knowledge of social roles. This property was absent in the first perspective- taking task of Experiment 2. The possibility that children's development of politeness is linked to certain aspects of social perspective-taking suggests that politeness may relate to still other measures of social perception, such as empathy (e.g., Gove \& Keating, 1979) and, perhaps, to social development in general.

Finally, we must add the necessary caution that even this form of social perspective-taking ability shared only a moderate relationship with continued development in the use and understanding of polite forms. Thus, although we are able to provide evidence that the development of politeness in speech may rest on more than linguistic ability alone, it seems that the identification and specification of the other factors involved in this ability have only just begun.

ACKNOWLEDGMENT 
The authors express appreciation to Helene Borke for providing details and photographs of the displays used in Borke (1975).

\section{REFERENCE NOTE}

1. LAKOFF, R. The logic of politeness or minding your p's and q's. Paper presented to the Chicago Linguistic Society, Chicago, 1973.

\section{REFERENCES}

BATES, E. Language and context: The acquisition of pragmatics. New York: Academic Press, 1976. BATES, E., \& SILVERN, L. Social adjustment and politeness in preschoolers. Journal of Communication, 1977, 27, 104-111.

BOCK, J., \& HORNSBY, M. How children ask and tell: A speech act analysis of children's requests. Papers and Reports on Child Language Development, 1977, 13, 72-82.

BORKE, H. Piaget's mountains revisited: Changes in the egocentric landscape. Developmental Psychology, 1975, 11, 240-243. BURGEMEISTER, B. B., BLUM, L. H., \& LORGE, I. Columbia Mental Maturity Scale manual. New York: World Book, 1954. CARROW, E. Screening Test of Auditory Comprehension of Language. Austin, TX: Learning Concepts, 1973.

DUNN, L. M. Peabody Picture Vocabulary Test. Circle Pines, MN: American Guidance Serviee, 1965. ERVIN-TRIPP, S. Wait for me, roller-skate. In C. Mitchell-Kernan \& S. Ervin-Tripp (Eds.), Child discourse. New York: Aeademic Press, 1977.

FISHBEIN, H., LEWIS, S., \& KEIFFER, K. Children's understanding of spatial relations: Coordination of perspectives. Developmental Psychology, 1972, 7, 21-33.

FLAVELL, J., BOTKIN, P., \& FRY, C. The development of role-taking and communication skills in young children. New York: Wiley, 1968.

FLUHARTY, N. B. Fluharty Preschool Speech and Language Screening Test. Boston: Teaching Resources Corporation, 1978.

GARVEY, C. Requests and responses in children's speech. Journal of Child Language, 1975, 2, 41-60. GOVE, F., \& KEATING, D. Empathic role-taking precursors. Developmental Psychology, 1979, 6, 594600.

JAMES, S. L. Effect of Listener age and situation on the politeness of children's directives. Journal of Psycholingustic Research, 1978, 7, 307-317.

LEE, L. Developmental Sentence Analysis. Evanston, IL: Northwestern University Press, 1974.

LOVEDAY, L. Pitch, politeness and sexual role: An exploratory investigation into the pitch correlates of English and Japanese politeness formulae. Language and Speech, 1981, 24, 71-89.

MAKOID, L. Are you asking me or telling me? A pragmatic aspect of early meaning. Paper presented at Boston University Conference on Language Development, Boston, 1977.

MARATSOS, M. Nonegocentric communication abilities in preschool children. Child Development, 1973, 44, 697-700.

READ, B., \& CHERRY, L. Preschool children's production of directive forms. Discourse Processes, 1978, 1, 233-246.

REEDER, K. The emergence of illocutionary skills. Journal of Child Language, 1980, 7, 13-28.

SCHATZOW, M., KAHANE, D., \& Youmss, J. The effects of movement on perspective taking and the coordination of perspectives. Development Psychology, 1980, 16, 582-587.

SHATZ, M., \& GELMAN, R. The development of communication skills: Modifications in the speech of young children as a function of the listener. Monographs of the Society for Research in Child Development, 1973, 38(Serial No. 152). 
STEPHENS, M. I. Stephens Oral Language Screening Test: Manual and technical report. Peninsula, OH: Interim Publishers, 1977. 